\title{
O popular e o canônico em “Campo Geral", de Guimarães Rosa
}

\author{
Maristela Kirst de Lima Girola*
}

\begin{abstract}
Resumo: O conto "Campo Geral" apresenta o sertão Abstract: The short story "Campo Geral" shows the brasileiro sob a perspectiva de uma criança, destacando Brazilian backwoods thought from the child's as relações humanas e familiares, as tradições e os perspective, emphasizing humane and familiar costumes populares, a música, a culinária e a relationships, popular traditions, music, cookery and religiosidade. $\mathrm{O}$ presente trabalho visa discutir os religiosity. This article aims at discussing the popular aspectos populares e canônicos, que se encontram and canonical aspects in this Rosa's text, analyzing the nesse texto de Guimarães Rosa, em relação à language, the structure and the theme.

linguagem, à estrutura e à temática.
\end{abstract}

Palavras-chave: Guimarães Rosa; Literatura Keywords: Guimarães Rosa; Brazilian Literature; Brasileira; Conto. Short Story.

Este ensaio propõe-se a discutir os aspectos populares e canônicos presentes em “Campo Geral”, de Guimarães Rosa (1956). Em um primeiro momento, procurar-se-á identificar traços de oralidade no texto em estudo. Em seguida, apresentar-se-á um levantamento de alguns dos costumes, tradições e crenças populares representados na obra.

"Campo Geral" trata da história de um menino chamado Miguilim, que vive com sua família no interior do Brasil, nos campos das "Gerais". O texto mostra a infância difícil do garoto, sua visão de mundo e a maneira de relacionar-se com os adultos, com as outras crianças e com os animais. Povoam o "universo" de Miguilim o pai duro e violento; a mãe carinhosa e envolvida com outros homens; os vários irmãos e irmãs, entre os quais se destaca "Dito", um pequeno sábio; a avó, Izidra, mulher forte, mas bondosa; as fiéis empregadas, amigas e boas cozinheiras; os animais domésticos e selvagens; os vizinhos curandeiros, entre outros. O narrador conta os fatos em terceira pessoa, mas em muitos momentos o leitor tem acesso aos pensamentos de Miguilim, podendo perceber os eventos, os personagens e o ambiente sob a ótica do protagonista. Guimarães Rosa (1956) mostra a visão particular de

\footnotetext{
* Maristela Kirst de Lima Girola é Mestre em Teoria Literária pela PUCRS. E-mail: stelanh@bol.com.br
} 
uma criança sobre a vida, e a narrativa não segue um fio linear, o que se coaduna com a natureza do olhar infantil, de acordo com Jeanne Marie Gagnebin (1994), que, em seu texto "A criança no limiar do labirinto", afirma:

O fio de Ariadne que guia a criança no labirinto não é somente o da intensidade do amor e do desejo; também é o fio da linguagem, às vezes entrecortado, às vezes rompido, o fio da história que nós narramos uns aos outros, a história que lembramos, também a que esquecemos e a que, tateantes, enunciamos hoje. (GAGNEBIN, 1994, p. 105)

Apesar da temática e da presença de traços de oralidade, a estrutura do texto não se assemelha à do conto popular ${ }^{1}$, pois não apresenta poucos personagens, por exemplo. Há também, contrariamente ao conto popular, a descrição dos personagens e do espaço onde se passa o enredo, como se verifica na passagem abaixo:

Mas sua mãe que era linda e com os cabelos pretos e compridos, se doía de tristeza de ter de viver ali. Queixava-se, principalmente nos demorados meses chuvosos, quando carregava o tempo, tudo tão sozinho, tão escuro, o ar ali era mais escuro; ou, mesmo na estiagem, qualquer dia, de tardinha, na hora do sol entrar. (ROSA, 1956, p. 15)

Todavia, a linguagem utilizada incorpora em seu léxico muitos vocábulos, expressões, verbos e marcas representativas da expressão oral popular, como nos exemplos a seguir: o uso da apóstrofe, para indicar a fusão de sons, "d’água" (Rosa, 1956, p. 15) e “que’é de” (idem, p. 28); interjeições típicas da região como "uai" (idem, p. 17); o diminutivo formado pelo sufixo "im" ao invés de "inho", como em "pertim" (idem, p. 26), "sozim" (idem, p. 28) e "papelim" (idem, p. 40); expressões desviadas da norma culta como "mais primeiro" (idem, p. 21), "pertencida de ninguém" (idem, p. 21), “com-cor” (idem, p. 21), "nem não era” (idem, p. 26), "queria a gente todos morresse juntos" (idem, p. 31); gírias como "chumbado" (idem, p. 34) e "mulher-à-toa" (idem, p. 35) para indicar bêbado e prostituta, respectivamente; alterações ortográficas como "especúla" (idem, p. 29) ao invés de especulador, "dechover" substituindo chover, "voroço" (idem, p. 27) no lugar de alvoroço e "açúcras" (idem, p. 65) ao invés de açúcares; o neologismo "começação" (idem, p. 57) em lugar de início; o particípio "morridos" (idem, p. 38) no lugar de mortos; o gerúndio "esmastigando" (idem, p. 59) ao invés de mastigando; o uso da locução "estava estando" (idem, p. 123) e ainda os verbos "ofrecesse" (idem, p. 85) e "percuravam" (idem, p. 93), em lugar de oferecesse e procuravam, respectivamente.

Além dos aspectos lingüísticos, é necessário destacar o grande número de elementos da cultura popular presentes no texto como lendas, canções, ditos populares, histórias de caçadas, hábitos alimentares e culinária típica, bem como aspectos religiosos e místicos. 
Pode-se citar como exemplo o personagem "Dito", irmão de Miguilim, que, como o seu próprio nome indica, sempre tinha um conselho a dar em forma de ditos populares: "O ruim tem raiva do bom e do ruim. O bom tem pena do ruim e do bom" (ROSA, 1956, p. 95). Há muitos outros ditos no texto, pronunciados por mulheres como "Fumaça pra lá, dinheiro p'ra cá (...) fumaça percura é formosura” (ROSA, 1956, p. 48-49), e outros repetidos pelos vaqueiros, "Hoje é dia de são-gambá: é de branco perder e preto ganhar" (ROSA, 1956, p. 73).

Verifica-se também a participação intensa dos animais no dia-a-dia das pessoas, resultando em muitas histórias de caçadas e em saberes populares provenientes da observação da lida diária. No início do texto, por exemplo, o leitor já se depara com uma crendice popular relacionada à proteção obtida por Miguilim através do sangue de um tatu:

Traziam o tatu, que guinchava, e com a faca matavam o tatu, para o sangue escorrer por cima do corpo dele para dentro da bacia (...) dizia que ele tinha estado muito fraco, saído de doença, e que o banho no sangue vivo do tatu fôra para ele poder vingar. (ROSA, 1956, p. 18)

A caça ao tatu, por sinal, é um dos costumes do povo do lugar, do qual Miguilim não gosta, como se percebe no trecho a seguir: "Mais que matavam eram os tatus, tanto tatu lá, por tudo (...) Tão gordotes, tão espertos - e estavam assim só para morrer, o povo ia acabar com todos?" (ROSA, 1956, p. 28). Mas outros animais também eram caçados. Os vaqueiros contavam muitas histórias de caçadas a Miguilim, como a que segue: "Veado foi acuado num capão-de-mato, não quis entrar no mato... Aí o veado tomou o chumbo" (ROSA, 1956, p. 76).

Os cachorros eram animais muito apreciados pelo povo, pois auxiliavam nas caçadas e protegiam as casas de animais perigosos. Suas maiores inimigas eram as jibóias, sobre as quais as pessoas conheciam várias histórias: "Jibóia, cobra, mais medonha de se pensar, uma sojigou o cachorrinho Floresto" (ROSA, 1956, p. 36).

Os bois também faziam parte da rotina da família: "Agora estavam reduzindo com os bezerros, para a ferra, na laçação. Miguilim também queria ir lá no curral, para poder ver" (ROSA, 1956, p. 54). A lida com o gado trazia lições para os trabalhadores. As experiências transformavam-se em sabedoria popular:

De primeiro, Miguilim tinha medo dos bois, das vacas costeadas. Pai bramava, falava: - 'Se um sendo medroso, por isso o gado te estranha, rês sabe quando um está com pavor, qualquer receiozinho, então capaz mesmo que até a mansa vira braba' (ROSA, 1956, p. 74).

Alguns animais inspiravam até poemas anônimos, como os vagalumes, por exemplo, que encantavam as pessoas e para os quais foram feitos os seguintes versos: "Vagalume,

\footnotetext{
${ }^{1}$ Como caracterizado por Câmara Cascudo, em Literatura oral no Brasil
} 
lume, lume, seu pai, sua mãe, estão aqui!...” (ROSA, 1956, p. 76).

$\mathrm{Na}$ obra, aparece ainda a música popular regional, as quadrilhas, como no exemplo que segue:

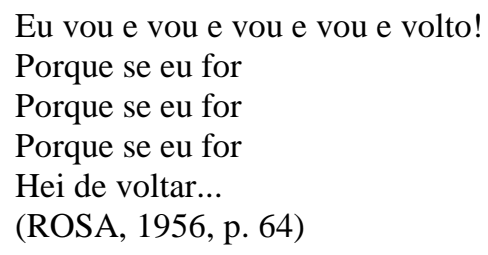

Porém, evidenciam-se também contos da cultura universal, como a história de João e Maria, que Miguilim conhecia: "Só o pai de Joãozinho mais Maria, na estória, o pai e a mãe levaram eles dois, para desnortear no meio da mata, em distantes, porque não tinham de comer para dar a eles. Miguilim sofria tanta pena, por Joãozinho mais Maria” (ROSA, 1956, p. 25). Há um momento da narração em que se percebe, no imaginário popular representado, um hibridismo cultural em relação às origens das histórias. Segundo Zilá Bernd (1995, p. 76), "o híbrido é aquilo que participa de dois ou mais conjuntos, gêneros ou estilos". É quando Siarlinda, mulher do vaqueiro Saluz, resolve contar algumas histórias para os meninos:

Siarlinda contou histórias. Da Moça e da Bicha-Fera, do Papagaio Dourado que era um Príncipe, do Rei dos Peixes, da Gata Borralheira, do Rei do Mato. Contou histórias de sombração, que eram as melhores, para se estremecer. Miguilim de repente começou a contar estórias tiradas da cabeça dele mesmo: uma do Boi que queria ensinar um segredo ao Vaqueiro, outra do Cachorrinho que em casa nenhuma deixavam que ele morasse, andava de vereda em vereda pedindo perdão. Essas estórias pegavam. (ROSA, 1956, p. 89)

Outro aspecto da cultura popular que enriquece a obra é a referência à culinária típica da região e aos hábitos alimentares do povo. Isso aparece em várias partes do texto, como nas passagens selecionadas que se encontram a seguir: "Vez em quando comiam, de sal, ou cocadas de buriti ${ }^{2}$, doce de leite, queijo descascado (...) tomava leite de cabra" (ROSA, 1956, p. 19); "Mamãe está fazendo creme de buriti, a Rosa está limpando tripas de porco, pra se assar" (ROSA, 1956, p. 20); "Punham o prato de comida para ele, na mesa, o feijão, arroz, couve, às vezes tinha torresmos, às vezes tinha carne-seca, tinha batata-doce, mandioca, ele mexia o feijão misturando com farinha-de-milho" (ROSA, 1956, p. 118).

Entretanto, o aspecto da cultura popular mais explorado é a religiosidade, que pode ser considerada híbrida, pois mistura crendices e superstições, catolicismo e misticismo africano. Tal aspecto verifica-se, por exemplo, no trecho em que Miguilim engasga-se com um pedaço de osso, o que faz com que ele siga uma simpatia religiosa: "Por simpatia em que alguma vez tinha ouvido falar (...) se benzia, bramando: - Em nome do Padre, do Filho e do Espírito 
Santo! (...) livre, do ossinho na goela estava todo salvo. - Que fé!” (ROSA, 1956, p. 33). Logo após esse episódio, menciona-se a empregada negra, Mãitina, que mantinha suas rezas de origem africana, mas era forçada pela avó de Miguilim a rezar no oratório para os santos católicos: “- Traste de negra pagã, encostada na cozinha, mascando fumo e rogando para os demônios dela, africanos! Vem ajoelhar gente, Mãitina!” (ROSA, 1956, p. 33). Percebe-se que Guimarães Rosa aproveita o sincretismo religioso como tema, contudo, não chega a explorar esse hibridismo de maneira estética, no sentido de alterar a própria estrutura da narrativa. De acordo com BERND (1995):

O sincretismo configura-se, pois, como uma das principais figurações do híbrido, constituindose em um dos fatores mais marcantes na trajetória da formação cultural da América Latina, correspondendo à fusão de elementos culturais distintos e até mesmo antagônicos, engendrando elementos novos. (...) $\mathrm{Na}$ literatura brasileira, embora temas e imagens das culturas africana e indígena tenham permeado a obra dos autores mais significativos desde o período colonial, formas verdadeiramente sincréticas que incorporem não somente imagens e/ou temas, mas também elementos que comprometam a própria estrutura da narrativa são relativamente recentes. (BERND, 1995, p. 77)

O oratório era comum nas casas da região, devido à forte religiosidade do povo. Em torno dele, as pessoas se reuniam para rezar: "Reunidos, de joelhos, diante do oratório. Até a mãe. Vovó Izidra acendia a vela benta, queimava ramos bentos, agora ali dentro era mais forte. Santa Bárbara e São Jerônimo salvavam de qualquer perigo de desordem" (ROSA, 1956, p. 32). Também aparece representada na obra a crença das pessoas em espíritos e fantasmas, evidente em algumas superstições: "Miguilim não gostava de pôr os olhos no escuro. Não queria deitar de costas, porque vem uma mulher assombrada, senta na barriga da gente. Se os pés restassem para fora da coberta, vinha mão de alma, friosa, pegava o pé” (ROSA, 1956, p. 37). Outra crendice popular presente na obra é relativa ao mau-olhado: “Esse era um menino maldoso, diabrava. '- Ele tem olho ruim', - a Rosa dizia - 'quando a gente está comendo, e ele espia, a gente pega dor-de-cabeça...” (ROSA, 1956, p. 40).

Os curandeiros, personagens comuns entre o povo, também estão retratados na obra, nas figuras de Seo Deográcias e Seo Aristeu. O primeiro, por exemplo, conhecia as ervas: "Com as ervas que sei, vai ser em pé um pau, garantia que dou, boto bom" (ROSA, 1956, p. 42). Porém, não eram só os curandeiros que tinham esses "poderes”. As mulheres também eram conhecedoras de procedimentos considerados curativos. Era o caso, por exemplo, da avó de Miguilim: "Vovó Izidra levou Tomézinho na horta, no lugar ofendido espremeu joão-leite, aquele leite azulado, que muito sarava" (ROSA, 1956, p. 93). A mãe de Miguilim, por sua vez, utilizava cristais: "Mãe trouxe a mula de cristal, branquinho, aplicou no lugar, aquela

\footnotetext{
${ }^{2}$ Fruto de uma palmeira
} 
friura lisinha do cristal cercava a dor para sarar, não deixava inchaço” (ROSA, 1956, p. 93). Mãitina, a empregada negra, era considerada pela família uma espécie de feiticeira, mas não recorriam aos seus préstimos, porque tinham medo e preconceito: "Eram santos-desgraçados, a gente nem devia de consentir se Mãitina oferecesse aquilo para respeito de se beijar, bonecos do demo, cazumbos, a gente devia era de decuspir em riba” (ROSA, 1956, p. 49).

O texto expõe ainda crenças incutidas nas crianças, visando à higiene pessoal: "Mas antes tinha carecido de lavar os pés: quem vai se deitar em estado sujo, urubu vem leva. Também tudo que se fazia transtornava preceito" (ROSA, 1956, p. 77). Há também os ditos populares religiosos, como este utilizado por Miguilim: “Com Deus me deito, com Deus me levanto!" (ROSA, 1956, p. 78).

Segundo Sílvia de Menezes Leroy (1997), em seu texto "Como se faz um mito - o sertão enquanto linguagem", há dois tipos de produção artística em torno do sertão, uma inerente à cultura sertaneja e outra que é a arte sobre o sertão, oriunda do Brasil instruído e letrado. Ainda de acordo com a estudiosa, na literatura, o sertão pode ser a matéria narrada ou o estilo, a linguagem. Levando-se em consideração as palavras de LEROY (1997), pode-se dizer que o texto de Guimarães Rosa relaciona-se ao segundo tipo de arte, pela própria trajetória de vida do autor ${ }^{3}$. Entretanto, o interessante é que na obra de Rosa o sertão está presente tanto como assunto, quanto como estilo.

Assim, o texto de Rosa é canônico, já que provém de um autor do Brasil instruído e letrado, mas o tema e o estilo são próximos ao popular. Nessa perspectiva, pode-se considerálo um texto híbrido. Segundo a interpretação de Nelson H. Vieira (2003) a respeito desse conceito, em seu texto "Hibridismo e alteridade: estratégias para repensar a História Literária", o mais importante no híbrido "não é a mistura, mas a colisão de diferentes pontos de vista" (MOREIRA, 2003, p. 103). Esses pontos podem ser provenientes de diferentes sistemas de linguagem. Além disso, ainda de acordo com VIEIRA (2003), o híbrido pode revelar diversas versões da memória cultural. Zilá Bernd (1998), em seu artigo "Em busca do terceiro espaço", a fim de definir o conceito, cita Sérgio Sant'Ana, que se refere a uma narrativa "complexa, plural, heterogênea onde impurezas, reapropriações, subversões, ambigüidades, equívocos e transgressões misturam-se, imbricam-se, confrontam-se" (BERND, 1998, p. 263).

Seguindo nessa direção, pode-se ainda considerar o texto de Rosa como um produto artístico que procura unir o canônico e o popular, gerando algo novo. Peter Burke (2003), em

\footnotetext{
${ }^{3}$ Cursou Medicina; estudou as línguas Alemã e Russa; seguiu carreira diplomática; em 1958, foi Ministro do Brasil e Chefe do Serviço de Demarcação de Fronteiras.
} 
seu livro Hibridismo Cultural, no terceiro capítulo intitulado "Variedade de situações", afirma que a troca cultural ocorre numa "zona de comércio" (BURKE, 2003, p. 70) que seria um espaço em que dois grupos distintos podem constituir uma base para o entendimento mútuo. Esse espaço também pode ser chamado de "entre-lugar". Silviano Santiago (1978), por exemplo, em seu artigo "O entre-lugar do discurso latino americano", abordando o papel do intelectual e os valores da América Latina rejeitados pelos centros de cultura, fala de um espaço intersticial a que ele chama de entre-lugar:

Entre o sacrifício e o jogo, entre a prisão e a transgressão, entre a submissão ao código e a agressão, entre a obediência e a rebelião, entre a assimilação e a expressão, - ali, nesse lugar aparentemente vazio, seu templo e seu lugar de clandestinidade, ali, se realiza o ritual antropófago da literatura latino-americana. (SANTIAGO, 1978, p. 28)

Guimarães Rosa, em seu papel de escritor e intelectual, propiciou aos leitores do Brasil e do mundo a descoberta do sertão, sem explorar somente o folclórico ou o exótico. Através de sua construção ficcional e de seu artesanato lingüístico, transformou o popular em cânone literário. Assim, Rosa pode ser considerado um dos autores que seguiu a tendência da literatura contemporânea de "exorcizar os fantasmas (estereótipos) elitistas e populares que promovem ideologias e preconceitos agressivos, fantasmas sociais que prejudicam a inclusão do popular como componente da cultura oficial" (BOSI apud VIEIRA, 2003, p. 111), apontada por Alfredo Bosi. "Campo Geral” é uma obra que pode ser relacionada a essa tendência, apresentando a característica de valorização do popular: "A literatura contemporânea começa a valorizar o que era considerado de mau gosto e pouco sofisticado (...) Incorpora os modos heterogêneos de ser na cena cultural brasileira" (BOSI apud VIEIRA, 2003, p. 111). Além disso, em "Campo Geral”, Rosa ousou mostrar o universo sertanejo por meio do olhar de uma criança. Dessa forma, mostrou o popular, tantas vezes afastado do que se considera cultura, sob a ótica de quem é periférico, inclusive, dentro da "periferia" cultural.

\section{Referências}

BERND, Zilá. Em busca do terceiro espaço. In: BERND, Zilá (Org.). Estruturas híbridasestudos em literatura comparada interamericana. Porto Alegre: Editora da UFRGS, 1998.

Inscrição do oral e do popular na tradição literária brasileira. In: BERND, Zilá (Org.). Fronteiras do literário: literatura oral e popular Brasil/França. Porto Alegre: Editora da UFRGS, 1995.

BURKE, Peter. Hibridismo cultural. São Leopoldo: Ed. UNISINOS, 2003. 
GAGNEBIN, Jeanne Marie. A criança no limiar do labirinto. In: GAGNEBIN, Jeanne Marie et al. História e narração em Walter Benjamin. São Paulo: Perspectiva, 1994.

LEROY, Sílvia de Menezes. Como se faz um mito - o sertão enquanto linguagem. In: CRISTOVÃO, Fernando. FERRAZ, Maria de Lourdes. CARVALHO, Alberto (Orgs.). Nacionalismo e regionalismo nas literaturas lusófonas. Lisboa: Cosmos, 1997.

ROSA, João Guimarães. Campo Geral. In: ROSA, João Guimarães. Corpo de baile (sete novelas). Rio de Janeiro: José Olympio, 1956.

SANTIAGO, Silviano. O entre-lugar do discurso latino-americano. In SANTIAGO, Silviano: Uma literatura nos trópicos: ensaios sobre dependência cultural. São Paulo: Perspectiva, 1978.

VIEIRA, Nelson H. Hibridismo e alteridade: estratégias para repensar a história literária. In: MOREIRA, Maria Eunice. (Org.). Histórias da literatura: teorias, temas e autores. Porto Alegre: Mercado Aberto, 2003. 